\title{
A educação e a racionalidade capitalista na atualidade: reflexões críticas de suas ideologias estruturantes
}

\begin{abstract}
Resumo: O objetivo deste artigo é promover o debate e a reflexão sobre a educação no atual período do Capitalismo. Entender a importância da educação para a reprodução desse sistema econômico. Analisamos ainda, como os discursos da Globalização e do Neoliberalismo participam deste processo. Entendemos que os discursos do encolhimento dos Estados Nacionais, da livre circulação e integração do mundo, se mesclam e se articulam para propagar a lógica do capital em todas as esferas sociais e a escola se configura como um dos espaços estratégicos dessa difusão. Com esse debate, procuramos participar de um desafio histórico de pensarmos em uma outra educação, com novas perspectivas que possam superar as determinações estruturais do capital.
\end{abstract}

\section{Education and the current capitalist rationality: critical thinking of their basic ideologies}

\begin{abstract}
The aim of this paper is to promote discussion and reflection on education in the current period of capitalism. To understand the importance of education for the reproduction of the economic system. We also analyzed, as the discourses of Globalization and Neoliberalism participate in this process. We understand that speeches about the shrinkage National States, free movement and integration of the world, mingle and relate to propagate the logic of capital in all spheres of society and the school is configured as one of the strategic areas of this diffusion. With this discussion, we join a historical challenge of thinking in another education with new perspectives that can overcome the structural determinations of capital.
\end{abstract}

* Graduado em Geografia pela Universidade Federal de São João Del Rei (UFSF).

**Professora Doutora do Departamento de Geografia da Universidade Federal de São João Del Rei (UFSF).

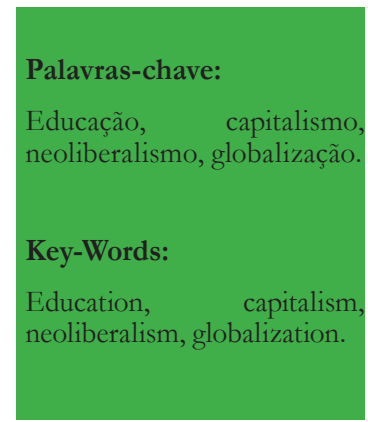




\section{Introdução}

Com o colapso da economia da União das Repúblicas Socialistas Soviéticas (URSS) e seu desmembramento em diversas repúblicas, reorientadas política e economicamente, ocorre um novo arranjo social sob os preceitos da economia de mercado. O capitalismo se torna hegemônico, com uma abrangência sem precedentes na história. Acompanhando a marcha de expansão do capital, um modelo de educação forjado sob os desígnios das relações capitalistas vem se mostrando imperativo nos estabelecimentos de ensino pelo mundo afora.

Neste artigo objetivamos discutir os caminhos trilhados pelos Estados capitalistas para manter o regime de acumulação, com a finalidade de levarmos à análise crítica da forma de organização e articulação do capital. Discutiremos também as ideologias e elementos discursivos que participam simbólica e objetivamente na reprodução do modelo de sociedade e de educação atuais; ideologias como a Globalização e o Neoliberalismo que estão em voga como elementos complementares e estruturantes do atual estágio de reprodução do sistema econômico capitalista. Fazemos um esforço para compreender em que esfera se dão as relações entre tais ideologias que, hora são apresentadas em um campo retórico, hora como materialidade concreta e como estas se complementam e se articulam em uma intencionalidade comum para sua reprodução.

O que assistimos atualmente, como modelo global e hegemônico de educação institucionalizada pelo Estado capitalista, são ações políticas que se prestam a reforçar a competitividade desenfreada entre os homens. O projeto de escola vigente expressa objetivamente os interesses da reprodução, do refazer-se cotidianamente a configuração sistêmica do capital, intensificando contradições que são, igualmente, naturalizadas todos os dias (MÉSZÁRS, 2005).

Entendemos que, para além dos desígnios exigidos pelo mercado, há outras relações desprendidas de intenções capitalísticas, que poderiam ser retrabalhados e resignificados, em uma perspectiva que transcenda a ótica funcionalista das atuais políticas públicas de educação.

\footnotetext{
"Educação" é uma palavra forte: "Utilização de meios que permitem assegurar a formação e o desenvolvimento de um ser humano; esses próprios meios". O termo "formação", com suas conotações de moldagem e conformação, tem o defeito de ignorar que a missão do didatismo é encorajar o autodidatismo, despertando, provocando, favorecendo a autonomia do espírito (MORIN, 2003, p. 10-11).
}

Nesse sentido, colocamo-nos o desafio histórico de refletir sobre uma educação emancipatória, que resgate a dignidade humana, de modo a transcender as determinações utilitaristas restritivas de uma educação e trabalho alienantes e permitir a socialização de conhecimentos, de inteligências, de experiências e de sentimentos para uma educação e trabalho para a vida, fonte de novas perspectivas.

\section{Algumas observações históricas do capitalismo e de seu projeto de educação}

Geografia Ensino \& Pesquisa, v. 17, n.3, p. 107-114, set/dez. 2013

A educação e a racionalidade capitalista na atualidade...

Da acumulação primitiva a atual fase do capitalismo, muitas transformações ocorreram, no entanto, a constituição estruturalmente desigual, alienante e repressora, em suas mais variadas formas, permanece como elemento basilar da essência e reprodução desse sistema, dando sequência ao acesso desigual aos recursos essenciais à vida humana (MÉSZÁRS, 2005).

No período feudal, a sociedade se estruturava na servidão completa e explícita dos servos aos seus senhores. Naquele momento, a religião se constituía no principal arcabouço da naturalização e internalização dessa ordem. A Igreja católica mantinha o monopólio de todo o conhecimento produzido, exercendo o poder de ensinar o que lhe era conveniente ou confinar este conhecimento quando ele ameaçasse a ordem estabelecida (DESROCHE, 1968). No entanto, os feudos foram abalados por transformações erigidas por contradições incontroláveis, que espalharam outra ordem por toda Europa, marcando o declínio do Regime Feudal e a ascensão do 
Mercantilismo. A Igreja já não podia mais conter ideias consideradas subversivas, mesmo tendo agido com todo empenho e rigor de que dispunha, como nos temerosos tribunais da Inquisição.

O movimento da Renascença pôs em marcha um levante de transformações socioeconômicas, políticas e culturais que desequilibrou toda estrutura de poder Feudal, questionando a ordem do mundo clerical e da imobilidade social do período, culminando em grandes revoluções culturais, políticas e econômicas. O capitalismo se afirma no seio dessas contradições/transformações com a nascente classe burguesa que logo se constitui como classe economicamente dominante. Desejando o domínio político, a burguesia questiona a ordem social fechada, os demasiados poderes da Igreja e os privilégios de uma nobreza ociosa e conservadora (SWEEZY; HOBSBAWN; DOBB; HILTON; et al., 1977) (ver mais em a "Transição do Feudalismo para o Capitalismo").

O conhecimento como monopólio da Igreja era utilizado como instrumento de legitimação, de mistificação, de construção do mágico, do sagrado como base de todas as coisas, de verdades absolutas que eram o sustentáculo da ordem Feudal. O Estado-Nação moderno vai se encarregar de educar a população, à medida que a Igreja se distancia dessa prerrogativa. A educação universal e gratuita vai ser então apontada como elemento crucial ao desenvolvimento econômico e propagação dos valores da burguesia. O Estado moderno capitalista, afinado a ideologia liberal, assume naquele momento, o papel da formação, da qualificação da população e transmutação do ensino religioso em ensino para o trabalho. O capitalismo surge como renovador das relações humanas, das relações de trabalho, das relações com o conhecimento e de visão de mundo.

Conforme Robert Kurz (2007), a configuração do Estado-Nação ocidental moderno e suas instituições governamentais capitalistas e a dinâmica e cultura da economia empresarial de mercado se alastraram em nível global. A instalação de um sistema educacional estruturado em padrões atinentes a lógica de mercado, contribuiu e prestou-se duplamente: como um eficiente mecanismo de disciplinamento (internalização de valores) e qualificação dos trabalhadores para o mercado de trabalho, mantendo certa "ordem" e propiciando formação elementar a mão de obra. Brandão afirma que "[...] A educação participa do processo de produção de crenças e de ideias de qualificações e especialidades que envolvem as trocas de símbolos, bens e poderes que, em conjunto, constroem tipos de sociedade" (1981, p.11).

\section{Ideologias estruturantes do atual estágio de reprodução do capital}

A crença na liberdade individual, na livre concorrência econômica da ideologia liberal, eclodiu no cerne das contradições da passagem do sistema socioeconômico de produção feudal para a sociedade mercantilista.

No capitalismo avançado, período chamado de Neoliberal, o Liberalismo advogado por John Locke, (1632 - 1704), Adam Smith (1723 - 1790) e outros pensadores que se ocuparam de defender a propriedade privada e o livre mercado, se veste com novas roupagens, colorida com novos matizes, um novo liberalismo, adaptado a um novo contexto histórico, político, ideológico e econômico. Ressurgem velhas ideologias transfiguradas, mas que, em essência, sustentam-se nas mesmas bases. No atual estágio de desenvolvimento do capitalismo, o termo liberdade, aspirado pelo homem no movimento Iluminista, é reconfigurado para liberdade de capitais e mercadorias (ANDERSON, 1995).

O liberalismo é um movimento de ideias que passa através de diversos autores
diferentes entre si, como Locke, Montesquieu, Kant, Adam Smith, Humboldt,
Constant, John Stuart Mill, Tocqueville (...) [cujos] aspectos fundamentais são o
econômico e o político, e por isso merecem estar sempre presentes. O liberalismo é,
como teoria econômica, defensor da economia de mercado; como teoria política, é
defensor do Estado que governe o menos possível ou, como se diz hoje, do Estado
mínimo (isto é, reduzido ao mínimo necessário) (BOBBIO, 2004, p. 128)

Ao chamado Estado mínimo seria atribuído o dever de defesa contra possíveis inimigos externos; a proteção jurídica contra qualquer tipo de ofensa aos direitos individuais e o gerenciamento e execução de qualquer empreendimento público, que não possa ser gerenciado ou executado pela
Geografia Ensino \& Pesquisa, v. 17, n.3, p. 107-114, set./dez. 2013.

Oliveira, J. S.; Toledo, M. R.

ISSN 2236-4994 
iniciativa privada (BEHRING; BOSCHETTI, 2007). O Estado mínimo defendido por esta ideologia busca, incessantemente, o máximo de possibilidades para garantir o regime de acumulação.

As políticas de cunho neoliberal ganham força principalmente a partir da crise econômica de 1968-1974. É bom lembrar que os neoliberais já anunciavam sua ideologia política e econômica desde muito antes, tendo suas primeiras formulações no período da Segunda Guerra Mundial (1939-1945), mas essas eram emudecidas pela expansão econômica do Pós-guerra, baseada no modelo fordista Keynesiano. Com a crise econômica e política do modelo Keynesiano, as ideologias neoliberais são recebidas com muito entusiasmo, sob a liderança britânica de Margaret Thatcher e americana de Ronald Reagan, tornando-se amplamente difundida como remédio para todos os males econômicos. Nesta etapa avançada do capitalismo ampliam-se a flexibilização do trabalho, as privatizações, a liberalização financeira, as desregulamentações e a fragilização dos Estados-nacionais, visando à liberação extensiva das atividades econômicas, compreendidas como produção, distribuição, troca e consumo, o chamado livre mercado (HARVEY, 2011).

A organização capitalista atual congrega forças para o redirecionamento de toda a sociedade à racionalidade sistêmica do capital, capitaneando as energias e inteligências para a construção de uma lógica reificadora e alienante, da qual educação faz parte, como um de seus constitutivos importantes. Os discursos do encolhimento dos Estados Nacionais, da livre circulação e integração do mundo, se mesclam e se articulam para propagar a lógica do capital em todas as esferas sociais. A escola se configura como espaço estratégico dessa difusão.

Harvey (1989) sugere que o capitalismo encontra-se em uma nova fase das relações de produção, apresentado como "acumulação flexível" ou "capitalismo tardio". Fase em que a financeirização e mercadificação das relações humanas se tornaram imperativos, cuja mobilidade e a fluidez se constituem como palavras de ordem, assim como a cultura do descartável, do fugaz.

\footnotetext{
A acumulação flexível foi acompanhada na ponta do consumo, portanto, por uma atenção muito maior às modas fugazes e pela mobilização de todos os artifícios de indução de necessidade e transformação cultural que isso implica. A estética relativamente estável do modernismo fordista cedeu lugar a todo o fermento, instabilidades e qualidades fugidias de uma estética pós-moderna que celebra a diferença, a efemeridade, o espetáculo, a moda e a mercadificação de formas culturais (HARVEY, 1989, p. 148).
}

Já o conceito de Globalização nos traz a ideia de interligação do sistema mundo; espaços conectados por artifícios tecnológicos de comunicação e transportes, atrelados por elementos comuns, inter-relacionados por conteúdos, vinculados em um verdadeiro sistema, como nas chamadas mídias sociais veiculadas pela internet e por todo o suporte tecnológico posto a serviço da velocidade e da difusão cada vez mais descentralizada e abrangente de conteúdos, construídos e disseminados coletivamente em um intenso sistema de interação.

Teóricos da Globalização alardeiam variados argumentos sobre tal fenômeno, chegando alguns a negá-la, ou a relativizá-la ou entende-la como discurso meramente ideológico enquanto outros reconhecem o fenômeno como marcante e presente na realidade atual. Alguns ainda argumentam que esse processo de Globalização é antigo, remontando a passagem da sociedade Feudal para o Capitalismo, quando o homem se lança aos mares em busca do "Novo Mundo", no chamado Mercantilismo. Há os que a definem simplesmente como processos econômicos de articulação, forjados pelo desenvolvimento tecnológico que permite intercâmbios de mercadorias e interações de pessoas em ordem planetária (IANNI, 1998).

De acordo com Milton Santos (2000), o espaço geográfico é constituído por um conjunto de

Geografia Ensino \& Pesquisa, v. 17, n.3, p. $107-114$, set/dez. 2013

A educação e a racionalidade capitalista na atualidade...
ISSN 2236-4994 sistemas de objetos e sistemas de ações interligados e interdependentes que vão tecendo no mundo uma malha de conexões, que o autor denomina de "meio-técnico-científico-informacional" (p. 139). No capitalismo, esses sistemas de objetos e de ações são criados para otimizar a propagação constante de capitais, de mercadorias e de informações. Nessa lógica, a inovação constitui-se como palavra de ordem, provocando uma tensão constante entre os sistemas de objetos e de ações. 
Lembramos aqui que, para Santos, não há um espaço global, mas, apenas "espaços da globalização" (2006, p. 227). Ou seja, existem pontos de densidade técnica, científica e informacional que são conectados e articulados pela exigência do sistema, enquanto muitos lugares são, parcialmente ou completamente, desprovidos de tais instrumentos de conexão. Milton Santos afirma que

Há espaços marcados pela ciência, pela tecnologia, pela informação, por essa mencionada carga de racionalidade; e há os outros espaços. Todavia, essa racionalidade sistêmica não se dá de maneira total, absoluta e homogênea, pois, nas áreas assim transformadas, permanecem zonas onde ela é menor ou inexistente (1996, p. 53).

Uma das particularidades do sistema capitalista atual é o maciço empreendimento em tecnologia no processo produtivo e na vida como um todo, acompanhado de uma engenharia de produção que vem sendo desenvolvida historicamente, passando da Revolução Industrial e do Fordismo para os modernos meios de produção que tem como força motriz a insaciável busca por lucros e a necessidade de manter a acumulação de capital já que essa sofre sucessivas crises, intrínsecas a sua racionalidade. Acompanhando esse desenvolvimento cientifico e tecnológico, a engenharia de exploração dos trabalhadores também vem sendo transformada ao longo do tempo, impondo novos métodos de trabalho, como no taylorismo (otimização do tempo de trabalho) e a chamada produção flexível (toyotismo) em uma constante necessidade de inovação do processo produtivo para atender a inerente competitividade e avidez exponencial sistêmica do capital (HARVEY, 1989).

Nessa rede de conexões, a identidade do trabalhador com o produto de seu trabalho se dispersa. A compreensão desse processo escapa da maioria das pessoas, pois o trabalho nas linhas de montagem confere, cada vez mais, um conhecimento restrito e especializado que, em muitas situações, restringe-se a um "apertar de parafusos", perdendo-se, desse modo, a identidade com o resultado do trabalho (MARX; ENGELS, 1998). Como parte integrante do sistema, a educação formalizada no sistema capitalista participa como formadora dos conhecimentos elementares para as necessidades específicas do mercado, junto ao seu papel de difusor de valores, de símbolos e de conformidades. "O discurso como base das coisas, nas suas propriedades escondidas e o discurso como base da ação comandada de fora, impelem os homens a construir a história através de uma práxis invertida" (SANTOS, 2000, p. 91-92).

Os constituintes produzidos nessa rede, inclusive o sistema educacional, são dotados de um discurso técnico, pragmático, especializado e funcional, com uma intencionalidade produtiva comercial e simbólica, na qual todas as ações são comandadas e direcionadas para a propagação da organicidade sistêmica, como nos diz Santos (1996), a uma solidariedade organizacional.

Educação/trabalho, trabalho/mercadoria, aí está a funcionalidade na racionalidade do capitalismo. Na racionalidade do capital, a educação formal tem um propósito bem definido, além de seu aspecto ideológico de construir consensos: a apropriação de conhecimentos técnicos determinados a serem vendidos no mercado de trabalho. Inversão da Educação e do trabalho e do tempo/espaço de sua fundamental possibilidade do exercício da emancipação. Educação/trabalho, tempo/ espaço constitutivos elementares e potenciais para a prática subversiva dos fatores condicionantes e determinantes da existência humana, são transformados e colocados sob as exigências do capital.

A experiência do tempo/espaço está na ordem da velocidade, da otimização da educação/trabalho. Supressão do tempo de reflexão e do espaço da experiência. Desse modo, a sociedade tem cada vez menos tempo, cada vez menos estudos abrangentes. O espaço é cada vez mais flú́do, cada vez mais dinâmico, cada vez mais fugidio, que nos parece escapar à experiência, subjugado ao dinheiro. Educação/trabalho, espaço/ tempo submissos ao capital e em constante tensão na urgência da novidade e da velocidade..

A demarcação de tempo/espaço na rotina das escolas é um dos elementos estruturantes, simbólicos e pragmáticos de disciplinamento dos alunos, impingindo a cultura da aceitação, do conformismo, da obediência, do "bom comportamento". Tempo/espaço mecânico, de modo que os alunos acostumem, desde cedo a respeitar os espaços e cumprir o tempo.

Geografia Ensino \& Pesquisa, v. 17, n.3, p. 107-114, set./dez. 2013.

Oliveira, J. S.; Toledo, M. R. 


\title{
A arquitetura do disciplinamento e do conformismo no tempo/espaço da escola
}

A arquitetura da grande maioria das escolas apresenta-se com uma curiosa similaridade: normalmente as salas de aulas são estruturadas em formas geométricas quadradas ou retangulares, que em seu interior, em uma das paredes, localiza-se a lousa, priorizando a visibilidade do professor sobre os alunos e que esse seja visto por todos. Com muita freqüência os prédios são sitiados por muros altos, grades e portões, constituindo um espaço reservado, retirado, teoricamente de domínio e gerência dos professores.

É muito curiosa a semelhança dos estabelecimentos escolares descrita acima com fábricas e presídios. "A disciplina procede em primeiro lugar à distribuição dos indivíduos no Espaço. Para isso, utiliza diversas técnicas. A disciplina às vezes exige a cerca, a especificação de um local heterogêneo a todos os outros e fechado em si mesmo" (FOUCAULT, 1987, p. 75).

A sirene das escolas, assim como das fábricas, anuncia o tempo de entrada nos estabelecimentos, anuncia o intervalo de refeições e o horário de saída, homogeneizando o tempo para otimizar os objetivos desejados, de modo que todos tenham a mesma obrigação de cumpri-lo, aceita-lo e seguir a rotina do tempo/espaço, mecânico, demarcado e homogêneo.

\begin{abstract}
A medição supõe um instrumento especial, o relógio, assim como uma unidade convencional, a hora. A medição do trabalho não é o trabalho, da mesma maneira que a medição do tempo não é tempo. Há, portanto, representação, porém relógio, objeto material, é o seu meio de suporte. O qual estabelece uma grande distância entre representação e a ideologia, ainda que o relógio implique uma ideologia; serve para transformar o tempo cíclico dos dias e das horas em tempo linear homogêneo; permite avaliar este tempo homogêneo em dinheiro, outra abstração concreta homogeizante, suporte de toda uma sociedade enquanto esta predomina como geradora de representações (LEFEBVRE, 1983, p. 33).
\end{abstract}

A gerência das escolas fica a cargo da diretoria que é responsável por fazer valer as determinações dos planos de educação básica estabelecidos pelos Estados, afinados a ideologia Neoliberal, promovida por grandes organismos internacionais, como FMI, Banco Mundial, entre outros. Aos professores fica o dever de por em prática a formação elementar dos alunos, baseados em tais planos. A escola vive o tempo da urgência, contabilizado em números, em valor de mercado. A rotina do tempo da escola prepara para a rotina do trabalho assalariado, na qual cada minuto é mensurado na contabilidade sistêmica do capital.

As normas estruturantes da organização do tempo da escola são fundadas em uma rede normativa, hierárquica e burocratizada, na qual as principais determinações são externas. Os conteúdos didáticos apresentados e discutidos obedecem a um tempo impessoal e homogeneizante, tempo mecânico. A escola do sistema capitalista se esforça para atingir o tempo do mercado, tempo frenético em detrimento do tempo da paciência, da disponibilidade. Não há tempo para o cuidado, para esperar, para experimentar, para se dispor em relações solidárias, pois o tempo que domina é o mecânico, o do relógio, o da velocidade, em que todos devem se adequar, se adaptar. As diferenças, a pluralidade de pessoas, de ideias, de vontades, de aptidões é regulamentada por um tempo único, que dispensa talentos e diferenças. O mais importante é cumprir os conteúdos do tempo homogeneizado.

\section{Considerações finais}

O que temos visto com a Globalização é o alcance cada vez mais extenso do capital em suas

Geografia Ensino \& Pesquisa, v. 17, n.3, p. 107-114, set/dez. 2013

A educação e a racionalidade capitalista na atualidade... ISSN 2236-4994 mais variadas formas, globalizando a cultura do consumismo, da financeirização e mercadificação de toda a vida, desestabilizando e apagando tradições em função de sua necessidade inerente de expansão. Enquanto para grandes empresas as fronteiras parecem coisas ultrapassadas, para a maior parte da população elas são cada vez mais significativas. Enquanto a livre circulação de capital e de mercadorias se torna cada vez mais abrangente com a quebra de regulamentações e de obstáculos à livre circulação do capital, ampliam-se políticas restritivas e xenofóbicas para restrição do livre fluxo de pessoas, 
permitindo apenas àqueles que podem arcar com as despesas da mobilidade, dos artifícios tecnológicos que viabilizam a locomoção global. Zygmunt Bauman (1999) nos alerta que na contemporaneidade o que se globaliza são as empresas transnacionais que se mostram cada vez mais desterritorializadas, livres para extrair o capital onde podem estar os maiores lucros, descompromissadas com as pessoas dos lugares, que por várias questões, mas fundamentalmente pela questão econômica, se mostram cada vez mais presas, atadas ao território, e para quem restam apenas os subprodutos da Globalização.

Diante de tal quadro, fica a pergunta: Como romper com a lógica reificadora do capital? Como subverter os planos e diretrizes curriculares para educação construído a partir de ideias predominantemente ligadas à ideologias conservacionistas da ordem vigente? Infelizmente não existem respostas prontas, acabadas, caminhos simples que possam nos esclarecer com adequada precisão o que fazer, não há formulas prontas. A história nos mostra que as respostas postas em prática até aqui, não se mostraram suficientes para superar as determinações do capital, mas na dialética dos acontecimentos podemos dizer que a questão se encontra em aberto, assim como nosso desafio. Oferecer resistência aos processos globalitários e neoliberais exige clareza de tais fenômenos, exercício crítico constante para compreender a totalidade da dinâmica do capital e para, assim, construirmos uma unidade e maturidade histórica da classe trabalhadora, como afirma Gramsci (2004) para elevar do "senso comum" para uma consciência crítica filosófica ou "bom senso", no sentido que essa assuma a vanguarda para uma nova práxis política.

Romper com a lógica do capital, com a exacerbada competitividade encarnada na luta de todos contra todos, como na metáfora de Hobbes (2005), com as ideologias e ditames institucionalizados, que dão sustentabilidade a esse sistema, que insistentemente nos coloca em estado de tensão, constitui um desafio histórico da humanidade. Construirmos uma educação para a vida, uma educação que transponha a formação técnica profissionalizante e contemple uma educação política, ética e humanitária apresenta-se como desafio na atualidade.

Restringir a técnica a um instrumento da força de trabalho a ser vendido no mercado, é reduzir a criatividade e a capacidade cognitiva humana a um exercício fútil e esvaziado que despreza sua força pulsante de transformação, de subversão de determinações naturais. Resgatar a dignidade humana constitui o princípio norteador que historicamente, em todas as práxis contra-hegemônicas, ganha uma nova dimensão em um fluxo aberto na história.

\begin{abstract}
[...] é somente quando a tomada de consciência implica a operação decisiva que o processo histórico deve efetuar em direção ao próprio fim. A função histórica da teoria consiste em tornar praticamente possível essa operação. Quando se dá uma situação histórica na qual o conhecimento exato da sociedade vem a ser, para uma classe, a condição imediata da sua autoafirmação na luta; quando, para esta classe, o conhecimento de si significa, simultaneamente, o conhecimento correto da sociedade, quando, em conseqüência, para um tal conhecimento, esta classe ao mesmo tempo sujeito e objeto, teoria e práxis se torna possível (LUKACS, 1987, p. 61)
\end{abstract}

Concomitantemente duas dimensões contraditórias se chocam no ambiente da escola: a dimensão balizada pelos desígnios do capital e uma solidariedade orgânica potencialmente subversiva que, nas sutilezas dos acontecimentos, expressa sentimentos e virtudes da natureza humana, fonte de outra racionalidade, que pode por em marcha uma nova forma de conceber a educação. Outras relações, desprendidas de intenções capitalísticas, florescem espontaneamente nas relações dos sujeitos da escola, em gestos de solidariedade, de receptividade, de disponibilidade, de afetividade, de esperança e de paixões que possibilitam uma nova escola, espaço privilegiado da pluralidade, da socialização de conhecimentos, de inteligências, de experiências e de sentimentos na elevação da consciência crítico-filosófica para superação dos imperativos do capital.

Geografia Ensino \& Pesquisa, v. 17, n.3, p. 107-114, set./dez. 2013.

Oliveira, J. S.; Toledo, M. R. 


\section{Referências}

ANDERSON, Perry. Balanço do neoliberalismo. In: SADER, Emir (Org.). Pós- neoliberalismo - As políticas sociais e o Estado democrático. Rio de Janeiro: Paz \& Terra, 1995.

BAUMAN, Zygmunt. Globalização e as Conseqüências Humanas. Rio de Janeiro, Jorge Zahar Editor, 1999.

BOBBIO, N. "A era dos direitos". In: BOBBIO, Norberto. A era dos direitos. Trad. Carlos Nelson Coutinho. Nova edição. Rio de Janeiro. Elsevier, 2004.

BRANDÃO, Carlos Rodrigues. O que é educação. São Paulo: Brasiliense, 2007.

DESROCHE, Henri. O Marxismo e as Religiões. Rio de Janeiro: Paz \& Terra, 1968.

FOUCAULT, Michel. Vigiar e punir: nascimento da prisão. Petrópolis: Vozes, 1987.

GRAMSCI, Antônio. Apontamentos para uma introdução e um encaminhamento ao estudo da filosofia e da História da cultura. Cadernos do Cárcere. v. 1. $3^{\mathrm{a}}$ ed. - Rio de Janeiro: Civilização Brasileira, 2004.

HARVEY, David. Condição Pós- Moderna. $7^{a}$ ed. São Paulo: Loyola, 1989.

HARVEY, David. O enigma do capital: e as crises do capitalismo. São Paulo: Boitempo, 2011. HOBBES Thomas. Leviatã ou Matéria, Forma e Poder de um Estado Eclesiástico e Civil. São Paulo: Martin Claret, 2005.

IANNI, Otávio. Globalização e neoliberalismo. São Paulo em Perspectiva. São Paulo: Fundação Seade, v.12, n.2, 1998, p. 27-32.

KURZ, Robert. O efeito colateral da educação fantasma. Primeira Versão, Ano VII, n. 217, v. XIX, 2007, p. 2-5.

LEFEBVRE, H. La Presencia Y La Ausencia. México D. F.: Fundo de Cultura Econômica, 1983.

LUKACS, G. Sociologia. Coleção Grandes Cientistas Sociais. São Paulo. Ática, 1987.

MARX, Karl; ENGELS, Friedrich. Manifesto do partido comunista. 10a ed. Petrópolis: Editora Vozes, 2000.

MÉSZÁRS, István. Educação para além do capital. São Paulo: Boitempo, 2005.

MORIN, Edgar. A cabeça bem-feita: repensar a reforma, reformar o pensamento. $8^{\mathrm{a}}$ ed. Rio de Janeiro: Bertrand Brasil, 2003.

SANTOS Milton. A Natureza do Espaço: Técnica e Tempo, Razão e Emoção. $4^{a}$ ed. São Paulo: Editora da Universidade de São Paulo, 2006.

SANTOS, Milton. Por uma outra globalização - do pensamento único à consciência universal. São Pauto: Record, 2000.

SANTOS, Milton. Técnica, Espaço, Tempo - Globalização e Meio Técnico-Científico informacional. São Paulo: Hucitec, 1996.

SWEEZY, Paul et al. A Transição do feudalismo para o Capitalismo. Rio de Janeiro, Paz \& Terra, 1977.

\section{Correspondência:}

Juliar Souza Oliveira

E-mail: juliar-stl@hotmail.com

Geografia Ensino \& Pesquisa, v. 17, n.3, p. 107-114, set/dez. 2013

A educação e a racionalidade capitalista na atualidade...
Recebido em 17 de setembro de 2012 .

Revisado pelo autor em 31 agosto de 2013.

Aceito para publicação em 04 de setembro de 2013. 